\title{
Response Normalization in the Superficial Layers of the Superior Colliculus as a Possible Mechanism for Saccadic Averaging
}

\author{
Corinne R. Vokoun, ${ }^{1}$ Xin Huang, ${ }^{2}$ Meyer B. Jackson, ${ }^{2}$ and Michele A. Basso ${ }^{3}$ \\ ${ }^{1}$ Molecular and Cellular Pharmacology Training Program and ${ }^{2}$ Department of Neuroscience, University of Wisconsin, Madison, Wisconsin 53706 and \\ ${ }^{3}$ Department of Psychiatry and Biobehavioral Sciences and Neurobiology, Semel Institute for Neuroscience and Human Behavior, University of California \\ Los Angeles, Los Angeles, California 90025
}

How does the brain decide where to look? Neuronal networks within the superior colliculus (SC) encode locations of intended eye movements. When faced with multiple targets, the relative activities of neuronal populations compete for the selection of a saccade. However, the computational principles underlying saccadic choices remain poorly understood. We used voltage imaging of slices of rat SC to record circuit dynamics of population responses to single- and dual-site electrical stimulation to begin to reveal some of the principles of how populations of neurons interact. Stimulation of two distant sites simultaneously within the SC produced two distinct peaks of activity, whereas stimulation of two nearby sites simultaneously exhibited a single, merged peak centered between the two sites. The distances required to produce merged peaks of activity corresponded to target separations that evoked averaging saccades in humans performing a corresponding dual target task. The merged activity was well accounted for by a linear weighed summation and a divisive normalization of the responses evoked by the single-site stimulations. Interestingly, the merging of activity occurred within the superficial SC, suggesting a novel pathway for saccadic eye movement choice.

Key words: global effect; nonlinear interactions; saccade direction; voltage imaging; weighted summation

\section{Introduction}

When faced with multiple options, how does the brain choose its course of action? Saccadic eye movements offer a model system for revealing the computations underlying this brain process. When a human or monkey is presented with two spots of light and must choose where to look, the saccadic system engages in two types of behavior. Time and distance permitting, saccades are made accurately to one of the two possible targets. In contrast, if the choice must be made quickly or the targets are close together, saccades often land in between the two spots of light. This phenomenon is referred to as the global effect, and saccades made to the intermediate location are called averaging saccades (Coren and Hoenig, 1972; Becker and Jürgens, 1979; Findlay, 1982; Ottes et al., 1984; Coëffé and O'Regan, 1987; van Opstal and van Gisbergen, 1990; Van Opstal et al., 1990; Glimcher and Sparks, 1993; Edelman and Keller, 1998; Chou et al., 1999).

\footnotetext{
Received July 16, 2013; revised April 7, 2014; accepted April 8, 2014.

Author contributions: M.B.J. and M.A.B. designed research; C.R.V. performed research; C.R.V. and X.H. analyzed data; C.R.V., X.H., M.B.J., and M.A.B. wrote the paper.

This work was supported by National Institutes of Health EY1019963 (M.A.B. and M.B.J.) and the Eye Research Institute (M.A.B. and M.B.J.). C.R.V. was supported in part by the Parkinson's Disease Foundation summer student fellowship program.

The authors declare no competing financial interests.

Correspondence should be addressed to Michele A. Basso, PhD, Department of Psychiatry and Biobehavioral Sciences Semel Institute for Neuroscience and Human Behavior UCLA Neuroscience Research Building, 635 Charles Young Drive. P.0. Box 957332, Los Angeles, CA 90095-7332. E-mail: mbasso@mednet.ucla.edu.

DOI:10.1523/JNEUROSCI.3022-13.2014

Copyright $\odot 2014$ the authors $\quad 0270-6474 / 14 / 347976-12 \$ 15.00 / 0$
}

Among the first attempts to understand the neural computations underlying saccadic averaging was work performed in the early seventies (Robinson, 1972). Electrical stimulation of single sites within the superior colliculus (SC) of an alert monkey resulted in fixed-vector saccades. Electrical stimulation of two sites simultaneously resulted in a single saccade that landed at a location between the two saccade locations resulting from stimulation of each of the single sites. The endpoint of the saccade was predicted by a weighted sum of stimulus intensities delivered to the two sites. Where the weighted sum is computed remains a mystery (van Opstal and van Gisbergen, 1990; Glimcher and Sparks, 1993; Edelman and Keller, 1998; Port and Wurtz, 2003).

To shed light on the mechanisms underlying dual-site electrical stimulation in the SC and saccade choice, we tested two hypotheses. First, is population activity generated by electrical stimulation integrated within the SC? Second, can integration be explained by linear summation or by some other model? We used voltage imaging of slices of the rat SC compared with psychophysics in humans performing a two-target saccade task. We found that the pattern of activity within the SC following dualsite stimulation appeared as a single, active population of neurons when the stimulation sites were in close proximity and that the distances in SC space required to produce a single or double peak of activation matched closely to the angular distances in visual space required to produce averaging or target-directed saccades in humans. Modeling the population of activity as a linear sum of activity resulting from the two sites failed to fit the data, 
whereas normalization of activity from the two sites provided a good fit. Surprisingly, normalization occurred within the superficial sensory layer. These results suggest a novel role for the superficial layers of the SC in saccade choice (Marín et al., 2005, 2007; Winkowski and Knudsen, 2007) and show that circuits within the SC, devoid of input from other areas, are capable of instantiating a computation involving divisive normalization like that seen in cortical areas and that has been shown to be important for many processes such as gain regulation and attention (Carnadini and Heeger, 2011).

\section{Materials and Methods}

In vitro procedures

Slice preparation. SC slices were obtained as described previously (Vokoun et al., 2010). Three- to 8-week-old rats were rendered unconscious by inhalation of $\mathrm{CO}_{2}$ and decapitated in accordance with the recommendations of the Panel on Euthanasia of the Veterinary Medical Association and the United States Public Health Service policy on the humane care and use of laboratory animals. All protocols were approved by the School of Medicine Animal Care and Use Committee of the University of Wisconsin-Madison. The brains were quickly removed and placed into icecold cutting solution consisting of the following (in mM): $124 \mathrm{NaCl}, 3.2$ $\mathrm{KCl}, 26 \mathrm{NaHCO}_{3}, 1.25 \mathrm{NaH}_{2} \mathrm{PO}_{4}, 1 \mathrm{CaCl}_{2}, 6 \mathrm{MgSO}_{4}, 10$ glucose, and 1.85 kynurenic acid, bubbled with $95 \% \mathrm{O}_{2}$ and $5 \% \mathrm{CO}_{2}$. Coronal slices $(350$ $\mu \mathrm{m}$ ) of midbrain were made using a vibratome and stored for $30 \mathrm{~min}$ in bubbled cutting solution at room temperature (RT). Slices were then transferred to bubbled artificial CSF (aCSF) for another 30-60 min at RT. The aCSF solution contained the following (in mM): $124 \mathrm{NaCl}, 3.2$ $\mathrm{KCl}, 26 \mathrm{NaHCO}_{3}, 1.25 \mathrm{NaH}_{2} \mathrm{PO}_{4}, 2.5 \mathrm{CaCl}_{2}, 1.3 \mathrm{MgSO}_{4}$, and 10 glucose. Before electrophysiological recordings in a submerged recording chamber superfused with bubbled aCSF at RT, slices were stained with the voltage-sensitive dye RH482 in bubbled aCSF $\left(0.05 \mathrm{mg} \mathrm{ml}^{-1}\right)$ for up to $45 \mathrm{~min}$ at RT.

Electrophysiology. Electrical stimulation was performed through aCSF filled glass capillary electrodes with 3-10 $\mu \mathrm{m}$ tip diameters. A $200 \mu \mathrm{s}$ single pulse stimulation was applied to the tissue by a Grass $S 88$ wave pulse generator and a Grass photoelectric stimulus isolation unit (Grass Technologies).

Voltage imaging. Optical signals were recorded as described previously, using a 464 channel fiber-optic photodiode system (Vokoun et al., 2010). Signals were amplified to $5 \mathrm{~V} \mathrm{nA}^{-1}$ of photocurrent, low-pass filtered at $500 \mathrm{~Hz}$, and digitized at a frame rate of $5 \mathrm{kHz}$ with a DAP 5200 data acquisition board (Microstar Laboratories). Slices were illuminated from below using a $100 \mathrm{~W}$ tungsten-halogen bulb driven by a Kepco ATE 36-30 DM power supply. Light passed through a $700 \pm 25 \mathrm{~nm}$ bandpass filter before reaching the tissue. Transmitted light was collected with a $10 \times$ Olympus objective (NA 0.4 ) or a $5 \times$ Zeiss objective (NA 0.25 ). Center-to-center distances of photodiodes were $\sim 67$ and $134 \mu \mathrm{m}$ for the $10 \times$ and $5 \times$ objectives, respectively. Images of the tissue were obtained with a charge-coupled device (CCD) camera. All recordings were reported as an average of four trials at $10 \mathrm{~s}$ intervals.

Data acquisition and preliminary signal processing were performed with a custom computer program that specifies acquisition parameters, shutter control, and stimulus protocols (Chang and Jackson, 2006). To limit light exposure to the tissue, a shutter opened $200 \mathrm{~ms}$ before the start of data acquisition, and remained open only for the length of the recording. Optical signals were displayed as a change in transmitted light intensity divided by the resting light intensity $(\Delta I / I)$. Noise in optical traces was reduced using a three-point binomial temporal filter and slow drift was corrected by fitting the baseline to a third-order polynomial. Spatial response maps with signal amplitude encoded as color were created from the maximum signal amplitude of each photodiode within a specified time window. For display only, signal amplitude was converted to color, and smoothed by linear interpolation and by applying a Gaussian spatial filter with a space constant of half the interphotodiode distance.

Data analysis. Data were exported to MATLAB for analysis (MathWorks). Single or double Gaussian functions were fitted to the raw data using a nonlinear least-squares method (Eqs. 1 and 2):

$$
\begin{gathered}
\mathrm{F}(\mathrm{x})=\mathrm{a} 1 * \mathrm{e}^{\frac{-(\mathrm{x}-\mathrm{b} 1)^{2}}{2 * \mathrm{c} 1^{2}}}, \\
\mathrm{~F}(\mathrm{x})=\mathrm{a} 1 * \mathrm{e}^{\frac{-(\mathrm{x}-\mathrm{b} 1)^{2}}{2 * \mathrm{c} 1^{2}}}+\mathrm{a} 2 * \mathrm{e}^{\frac{-(\mathrm{x}-\mathrm{b} 2)^{2}}{2 * \mathrm{c} 2^{2}}},
\end{gathered}
$$

where $\mathrm{a} 1$ and $\mathrm{a} 2$ are maximum amplitude values, b1 and b2 are center values, and $\mathrm{c} 1$ and $\mathrm{c} 2$ are SDs. In the event that Gaussian functions were not well fitted to the data for population analysis (Fig. 8), as assessed by a coefficient of determination $\left(R^{2}\right) \leq 0.8$, data points were smoothed with a moving average filter, spanning 5 data points. If the Gaussian fit was still poor after smoothing, points falling within $\pm 100 \mu \mathrm{m}$ of the stimulation site were omitted from the dataset to ensure good fits.

To evaluate the relationship between responses to dual- and single-site stimulation, we fitted the responses using four models. In the first model, the dual-site stimulation responses were fitted with a weighted linear sum of the single-site stimulation responses (Eq. 3):

$$
R_{1,2}=w_{1} R_{1}+w_{2} R_{2}+c
$$

where $R_{1,2}$ represents the responses evoked by stimulation delivered simultaneously to both sites 1 and 2 , and $R_{1}$ and $R_{2}$ represent responses evoked by single-site stimulation presented to site 1 and site 2 , respectively. $w_{1}$ and $w_{2}$ are the response weights, $c$ is a constant.

We next fitted the responses using a divisive normalization model, in a form similar to the contrast normalization model used in visual cortex (Busse et al., 2009):

$$
R_{1,2}=\frac{I_{1}^{n} F_{1}+I_{2}{ }^{n} F_{2}}{\left(\sqrt{I_{1}^{2}+I_{2}^{2}}\right)^{n}+\sigma^{n}}+c
$$

where $I_{1}$ and $I_{2}$ represent the stimulation strengths at the two stimulation sites, $n$ is an exponent variable, $\sigma$ is a positive constant, and $F_{1}$ and $F_{2}$ represent responses evoked by single-site stimulation presented to site 1 and site 2, respectively. Note that the divisive normalization model is a specific form of the linear weighted sum model as shown in Equation 3, with the response weights determined by the following:

$$
w_{1}=\frac{I_{1}{ }^{n}}{\left(\sqrt{I_{1}{ }^{2}+I_{2}{ }^{2}}\right)^{n}+\sigma^{n}}, \quad w_{2}=\frac{I_{2}{ }^{n}}{\left(\sqrt{I_{1}{ }^{2}+I_{2}{ }^{2}}\right)^{n}+\sigma^{n}} .
$$

To evaluate nonlinearity in the relationship among the dual- and the single-site stimulation responses, we also fitted the responses with two nonlinear models. In one model, we added a nonlinear interaction term to the weighted linear sum model (Sanada et al., 2012):

$$
R_{1,2}=w_{1} R_{1}+w_{2} R_{2}+b R_{1} R_{2}+c,
$$

where $b$ is the weight for the nonlinear interaction. In another model, we fitted the data with a power-law summation (Heuer and Britten, 2002):

$$
R_{1,2}=\left(w_{1} R_{1}^{n}+w_{2} R_{2}^{n}\right)^{1 / n}+c .
$$

The two nonlinear models each have one additional free parameter compared with the weighted linear sum model. For each model, the goodness-of-fit was calculated by taking the square of the correlation coefficient between the measured responses and the model fits. To compare the weights fitted to the responses recorded in the superficial and intermediate layers using the linear weighted sum model (Eq. 3 ) and the normalization model (Eq. 4), we pooled the response weights $w_{1}$ and $w_{2}$.

Interstimulus distances were calculated by first determining the location of stimulation for each stimulating electrode. Distances from the stimulating electrodes to each photodiode were calculated as the length of a straight line from the center of the photodiode corresponding to a site of stimulation to the center of selected photodiodes, assuming a regular hexagonal geometry for the 464 channel photodiode array. Due to the curved nature of the laminae in the SC, the selected diodes along a mediolateral contour were adjusted to a straightened axis for plotting. Next, the interstimulus distance was calculated, and all values were ad- 
justed such that the two stimulus locations were equidistant from the zero value on the mediolateral axis. In other words, interstimulus distance zero is perfectly centered between the two stimulating electrodes.

Visual space coordinates $(R, \Phi)$, were calculated from collicular coordinates $(u, v)$ using equations modified from Ottes et al. (1986):

$$
\begin{gathered}
R=A \sqrt{\exp \left(\frac{2 u}{B_{u}}\right)-2 \exp \left(\frac{u}{B_{u}}\right) * \cos \left(\frac{v}{B_{v}}\right)+1,} \\
\Phi=\operatorname{atan}\left[\frac{\exp \left(\frac{u}{B_{u}}\right) * \sin \left(\frac{v}{B_{v}}\right)}{\exp \left(\frac{u}{B_{u}}\right) * \cos \left(\frac{v}{B_{v}}\right)-1}\right],
\end{gathered}
$$

where $B_{u}(\mathrm{~mm})$ and $B_{v}\left(\mathrm{~mm} \mathrm{deg}^{-1}\right)$ are scaling constants used to determine the size of the collicular map along the $u$ (rostrocaudal) and $v$ (mediolateral) axes, and $A(\mathrm{deg})$ is a constant which, along with the ratio of $B_{u} / B_{v}$, is used to determine the shape of mapping. In this case, anisotropic mapping parameters modified to approximate the dimensions of the rodent SC were used (Siminoff et al., 1966) $\left(B_{u}=1.0, B_{v}=1.3\right.$, and $A=3.0)$. It was assumed based on sensory and motor maps that coronal slices contained neurons that responded with approximately isoeccentric $(R)$ metrics, based on their linearity within the $u$ axis. For this reason, $u$ was set to $2 \mathrm{~mm}$ in all cases. This value of $u$ approximates an anatomical position from which slices were obtained because precise coordinates $(u$, v) could not be measured.

\section{In vivo behavioral procedures}

Eye movement recordings. The protocol for experiments using human eye tracking was approved by the Institutional Review Board. Data acquisition and visual stimulus generation were controlled by the computer programs Rex and Vex, developed and distributed by the Laboratory of Sensorimotor Research at the National Eye Institute (Hays et al., 1982). Vertical and horizontal eye movements were monitored and saved to a hard disk with 16-bit resolution at a sampling rate of $1000 \mathrm{~Hz}$. Eye movements of subjects seated $50-70 \mathrm{~cm}$ from a 19 inch CRT display were tracked using the EyeLink 1000 system (SR Research). Visual stimuli were displayed at $8^{\circ}$ eccentricity. Subjects were healthy males and females, between 25 and 45 years of age with 20/20 vision or corrected to $20 / 20$ vision. Subjects were instructed to make an eye movement as quickly and as accurately as possible. All experiments were performed in dim ambient light (luminance $<1 \mathrm{~cd} \mathrm{~m}^{-2}$ ), and each recording session lasted $\sim 1$ to $1.5 \mathrm{~h}$.

After fixating on a centrally located spot $\left(0.4^{\circ}\right.$ diameter, white, luminance $=51.8 \mathrm{Cd} \mathrm{m}^{-2}$ ) displayed on a gray background (luminance $=$ $2.9 \mathrm{Cd} \mathrm{m}^{-2}$ ) for a random time within $100-150 \mathrm{~ms}$, either a single stimulus or paired stimuli $\left(0.6^{\circ}\right.$ diameter, white, luminance $=51.8 \mathrm{Cd}$ $\mathrm{m}^{-2}$ ) appeared and the central spot disappeared. The stimuli stayed on until the end of the trial. Single targets were presented in two-thirds of the trials. The position of the single target stimulus was selected randomly from 30 possible positions, at $10^{\circ}$ intervals, omitting $\pm 10^{\circ}$ around the vertical meridian. Dual targets were presented at angular separations of $30^{\circ}, 40^{\circ}, 50^{\circ}, 60^{\circ}, 70^{\circ}$, and $80^{\circ}$. Twelve arrangements were selected for each category of dual stimuli, with targets displayed only at locations in which single target trials were also recorded. Audible beeps were presented to indicate when the subject completed a correct trial. Acceptance windows with a width of $10^{\circ}$ and a height of $20^{\circ}$ were used to record eye movements to the target hemifield as correct trials and eye movements to the opposite hemifield as error trials.

Data analysis. Data collected by the EyeLink and Rex computers were exported to MATLAB for analysis. Trials with blinks or anticipatory saccades (beginning $<75 \mathrm{~ms}$ after fixation point extinction) were excluded. Saccade initiation was determined as the point where the horizontal or vertical eye trace exceeded a velocity of $30^{\circ} \mathrm{s}-1$. Because multiple saccadic movements were often made with brief periods of fixation separating movements, saccade endpoints were determined as the location of the eye $35 \mathrm{~ms}$ after the first saccade initiation. Movement traces were corrected for starting position deviations by adjusting the location of the eye while fixating ( $20 \mathrm{~ms}$ before saccade initiation) to a
(Rho, $\Phi)$ of $(0,0)$. For final analysis, all dual target conditions were rotated to $\Phi$ of $0^{\circ}$.

\section{Results}

Application of a single pulse of electrical stimulation to the intermediate layers of the SC evoked responses with a consistent pattern of spread as reported previously (Vokoun et al., 2010). Briefly, stimulation within the intermediate layers produced optical signals that spread $\sim 250 \mu \mathrm{m}$ medially and laterally within a circumscribed region within the intermediate layers (Fig. 1). Optical signals extended into the superficial layers and then spread $\sim 600 \mu \mathrm{m}$ medially and laterally (Fig. $1 B, C$ ). Our previous work demonstrated that these signals result from synaptic activity (Vokoun et al., 2010) and our more recent work shows that the spread of activation from intermediate layers into the superficial layers is mediated by a novel excitatory pathway from the stratum griseum intermediale (SGI; intermediate layers) to the stratum griseum superficiale (SGS; superficial layers; Ghitani et al., 2012).

To explore how SC neuronal circuits integrate activity arising from multiple sites, we stimulated two sites in the SGI simultaneously. The response pattern to dual stimulation showed very little mediolateral spread within the SGI, defining two distinct regions of activation (Fig. 1D). The activity arising from both sites of the SGI extended into the SGS. Figure $1 D$ shows that it was within the SGS where the two regions of activation converged, with activity appearing maximally at a region located approximately midway between the stimulation sites (Fig. 1D). Consistent with action potential conduction velocity and synaptic transmission delays, the time necessary for the two populations to merge at an intermediate location within the SGS was $5.8-7 \mathrm{~ms}$ (Fig. 2), with a conduction velocity between laminae of $\sim 0.07$ $\mathrm{m} / \mathrm{s}$. The mean interlaminar conduction velocity following dualsite SGI stimulation was $\sim 0.11 \mathrm{~m} / \mathrm{s} \pm 0.02(n=7$ slices, 14 stimulation sties), which is equivalent to previously reported values and consistent with orthodromic activation (Vokoun et al., 2010).

To quantify the spatial pattern of activation across the SC, we plotted the signal amplitude measured as the change in transmitted light intensity divided by the resting light intensity $(\Delta I / I)$ across the mediolateral extent of the tissue in both the SGS and the SGI in response to stimulation in the SGI. Figure 3, $A$ and $D$, shows these plots for each of the two single stimulation sites from the slice shown in Figure 1 (Fig. 3A, SGS; D, SGI). Each stimulation site resulted in discrete peaks that were fit well by Gaussian functions centered near the stimulation site (Fig. 3A, blue Gaussian centered at $-217 \mu \mathrm{m}$ and yellow Gaussian at $138 \mu \mathrm{m}$; D, blue Gaussian centered at $-243 \mu \mathrm{m}$ and yellow Gaussian at $273 \mu \mathrm{m}$ ). Dual-site stimulation of the SGI elicited different patterns of activation in the SGI and SGS (Fig. $3 A, D$, red). In the SGS, the activation appeared as a single region of activity centered close to the location in the SGS between the two stimulation sites in the SG (Fig. 3A, $-87 \mu \mathrm{m}$, red; mean location of blue and yellow sites $=-39 \mu \mathrm{m})$. In contrast, the two sites of activation remained distinct within the SGI (Fig. 3D, -252 and $251 \mu \mathrm{m}$, red). To confirm that this finding was not unique to this slice, we measured the pattern of activation in response to dual stimulation in the SGI in seven slices with similar interstimulus distances (mean SGI interstimulus distance $\pm \mathrm{SD}=513 \pm 54 \mu \mathrm{m}$ ). Figure $3, B$ and $E$, shows that these slices had similar activity patterns as shown in Figure $3 A$ and $D$. Across the sample of seven slices, the mean location of the peak response in the superficial layers resulting from dual stimulation (as measured from the centers of each Gaussian fit) was $9 \pm 102 \mu \mathrm{m}$. We then measured the cen- 


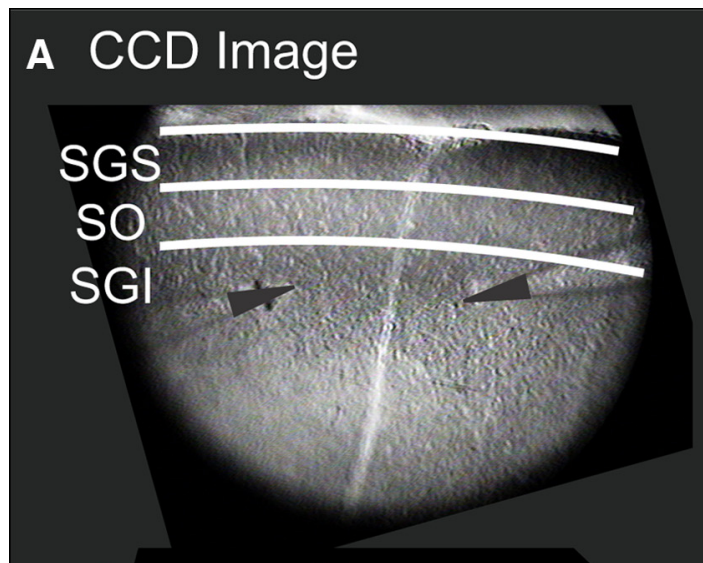

B Stimulus \#1

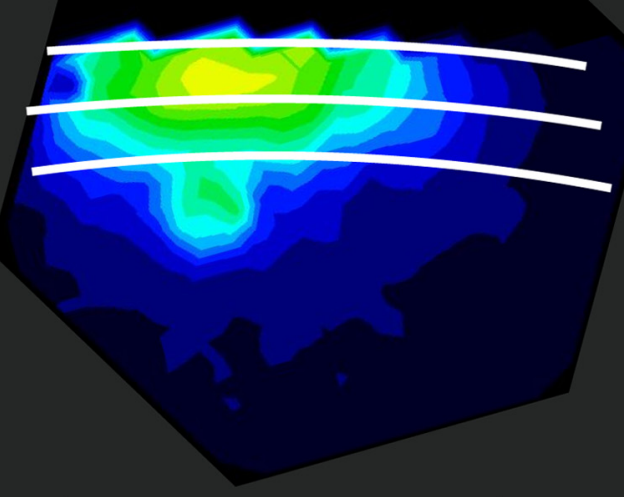

\section{c Stimulus \#2}
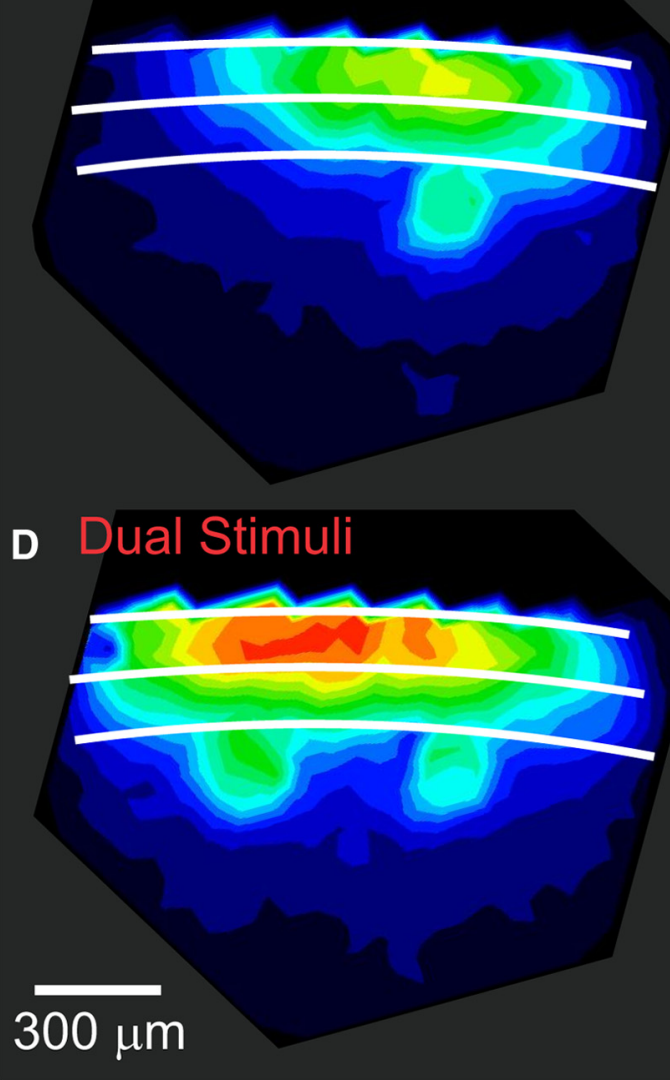

Figure 1. Dual-site stimulation results in integrated activity. $A, C C D$ image of $S C$. White lines denote the borders between layers in all parts: SGS, SO (stratum opticum), and SGI. Arrowheads

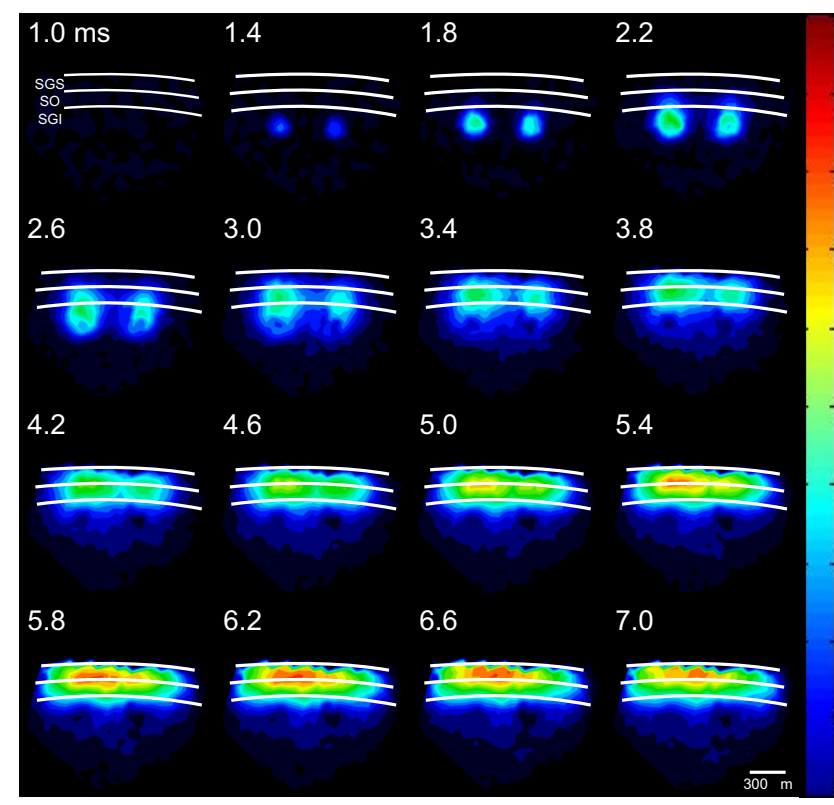

Figure 2. Integrated signals appear quickly. Serial images of response amplitude 1-7 ms after dual-site stimulation show the spatial and temporal dynamics of signals throughout the slice. Signal amplitude $(\Delta / / /)$ is encoded as color as in Figure 1 . White lines and labels designate approximate boundaries of the laminae (see Fig. 1A). Scale bar, $300 \mu \mathrm{m}$.

ters of each of the individual stimulation sites and determined this mean. The mean center for the blue stimulus was $-195 \pm 86$ $\mu \mathrm{m}$. The mean center for the yellow stimulation site was $223 \pm$ $112 \mu \mathrm{m}$. Taking the average of these means yields a predicted center of $14 \pm 79 \mu \mathrm{m}$ for dual stimulation. These actual and predicted center locations were statistically indistinguishable (Wilcoxon rank sum, $p=0.90$ ). In contrast to those in the SGS, the location of the peak responses in the SGI were statistically indistinguishable from the location of response peaks with individual sites of stimulation (blue stimulation site $=-252 \pm 47$ $\mu \mathrm{m}$ and the red left site $=-255 \pm 27 \mu \mathrm{m}$; Wilcoxon rank sum, $p=0.71$; yellow stimulation site $=305 \pm 103 \mu \mathrm{m}$ and the red stimulation site $=248 \pm 38 \mu \mathrm{m}$; Wilcoxon rank sum, $p=0.32$ ). These findings support the conclusion that at a particular interstimulus distance, stimulating two locations simultaneously in the SGI results in a single, merged peak of activity in the SGS appearing at a location intermediate between the two stimulated SGI locations. In contrast, the same stimulation results in two spatially discrete populations of activity within the SGI.

We next wanted to understand the manner in which the activity in the SC map was integrated. One possible way is that the activity arising from the two separate sites could summate linearly resulting in a peak that is larger than either of the single peaks alone. Alternatively, the peak could be scaled in some manner. Figure $3 C$ plots for seven slices, the amplitude parameter (a1) of a Gaussian fit to the dual stimulation data against the amplitude parameter of a Gaussian fit to the linear sum of the two stimulation sites (predicted results for a linear sum model). All the points lie above the unity line indicating that the actual response to dual-site stimulation was always smaller than that pre-

$\leftarrow$

show the stimulating electrodes. $\boldsymbol{B}$, Spatial response map with signal amplitude $(\Delta / / I)$ encoded as color following single-site electrical stimulation 1. Dark red (warm) indicates high signal and dark blue (cold) indicates low signal. C, D, Same as in $\boldsymbol{B}$, following electrical stimulation at site 2 and following dual-site stimulation, respectively. Scale bar, $300 \mu \mathrm{m}$. 
dicted by a linear sum. Across the sample, the predicted and actual Gaussian amplitude values were significantly different (signed rank test, $p=0.016$ ). This indicates that some scaling of the responses occurs within the SC circuits. Since the SGI dual stimulation data were more accurately fit with a double Gaussian curve, both amplitude parameters (a1 and a2) were plotted in Figure 3F. Both a1 (circles) and a2 (squares) data points fell along the unity line, indicating a lack of scaling in the SGI following dual stimulation. The amplitude values for each Gaussian were not significantly different between the actual and predicted (signed rank test; al, $p=0.69 ; \mathrm{a} 2, p=0.81)$.

Since a simple summation model did not fit the data in SGS well, we tested a linear weighted sum model to fit the responses and determined the response weights (Eq. 3). In general, the linear weighted sum model provided excellent fits of the responses. The goodnessof-fit measured by the coefficient of determination $\left(R^{2}\right)$ was 0.97 for the fitted SGS responses from the single slice example and had a mean value of $0.83 \pm 0.20$ for the fitted responses in the SGS for 20 slices. For the SGI data, the $R^{2}$ value for the single slice was 0.96 whereas for the sample of 20 slices the $R^{2}$ was $0.84 \pm 0.11$. Adding a nonlinear interaction term to the linear weighted sum model (Eq. 5) or using a power-law summation model (Eq. 6; Heuer and Britten, 2002) increased the goodness-of-fit modestly. The mean $R^{2}$ increased from 0.83 to 0.89 for both nonlinear models in the SGS, and from 0.84 to 0.85 and 0.86 for the two nonlinear models, respectively, in the SGI. The modest increase is despite the fact that these two nonlinear models used one more parameter than the linear model. The mean weights ( $w_{1}$ and $w_{2}$ pooled) for the SGS and SGI for the linear weighted sum model were $0.57 \pm 0.16$ and $0.87 \pm 0.2$, respectively. The weights for the SGS fits were significantly smaller than those for the SGI responses (one-tailed paired $t$ test, $p=1.7 \times 10^{-9}, n=40$ ).

To evaluate whether the response weights could be accounted for by a computation of divisive normalization (Carandini et al., 1997; Busse et al., 2009; MacEvoy et al., 2009; Carandini and Heeger, 2011), we fitted the responses using a divisive normalization model, similar to the contrast normalization model used to describe visually evoked responses in the visual cortex (Busse et al., 2009). In our model, the weight for the response elicited at one stimulation site was determined by the stimulation strength at that site, normalized by the overall stimulation strengths at both sites (Eq. 4). The divisive normalization model fitted the responses nearly as well as the linear weighted sum model. The black curves fitted to the red points in Figure 3 illustrate the normalization model fits to the dual-site stimulation responses. The goodness-of-fit $\left(R^{2}\right)$ was 0.94 for the fitted SGS responses from the single slice example (Fig. $3 A$ ) and had a mean value of black).
B


E

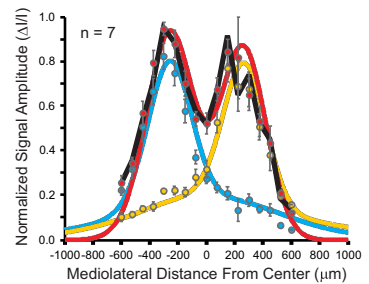

E

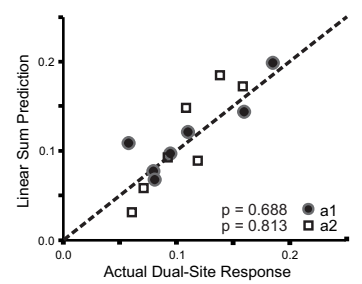

Figure 3. Dual-site stimulation responses are integrated in the superficial SC. $A$, Signal amplitude $(\Delta / / I)$ measured in the SGS for a single slice is plotted across the mediolateral extent of the SC following single-site (blue and yellow) and dual-site (red) stimulation in the SGI. Data were fitted with Gaussians (Eq. 1) indicated by the colored lines. Black lines show the divisive
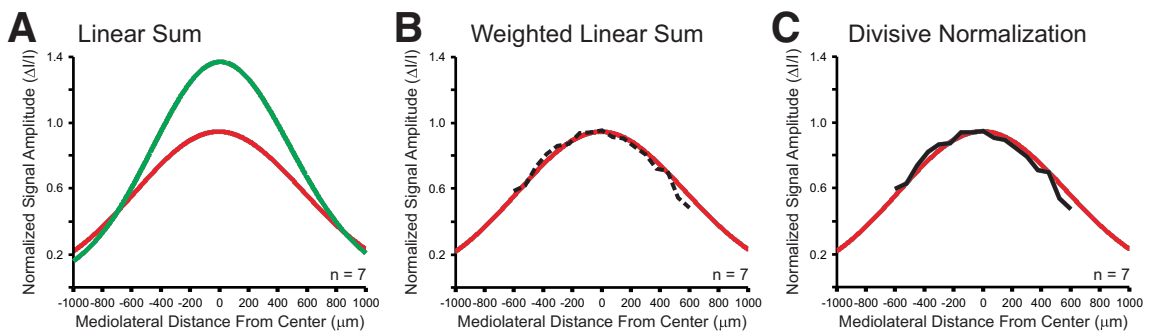

Figure 4. Dual-site stimulation responses are well explained by divisive normalization. $\boldsymbol{A}$, Comparison of population $(n=7)$ supeficial layer signal amplitude $(\Delta / / /)$ resulting from dual-site stimulation in the intermediate layer (red) and linear summation of individual stimulation sites (green). Both datasets were fitted with Gaussians. B, Same as $\boldsymbol{A}$, comparing Gaussian fitted, dual stimulation data (red) to the weighted linear sum model (dashed black). $\boldsymbol{C}$, Same as $\boldsymbol{B}$, for the divisive normalization model (solid

$0.82 \pm 0.22$ for the fitted responses in the SGS for 20 slices. For the SGI data, the $R^{2}$ value for the single slice was 0.92 (Fig. $3 D$ ) whereas for the sample of 20 slices the $R^{2}$ was $0.82 \pm 0.12$. The mean weights ( $w_{1}$ and $w_{2}$ pooled) for the SGS and SGI obtained using the normalization model were $0.67 \pm 0.18$ and $0.84 \pm 0.11$, respectively, consistent with the weights obtained using the linear weighted sum model. The weights for the SGS responses using the normalization model fits were significantly smaller than those for the SGI responses (one-tailed paired $t$ test, $p=1.3 \times 10^{-6}$, $n=40$ ). This latter result suggests that response normalization is stronger in SGS than in SGI. Assuming normalization in the SC results from GABAergic circuits, this latter result is consistent with the higher levels of GABA in the SGS than the SGI (Appell and Behan, 1990; Mize, 1992; Behan et al., 2002). Note that although the data shown in Figure 3, $B$ and $E$, are from seven slices with similar interstimulus distances, the experiment was replicated in 20 slices with a wider range of interstimulus distances and stimulation strengths. These results indicate that the activation pattern produced by dual-site stimulation is significantly smaller than a simple sum of the activity evoked by single-site stimulations, consis- 
Symmetrical Stimulation

A Full current $(100 \mu \mathrm{A})$

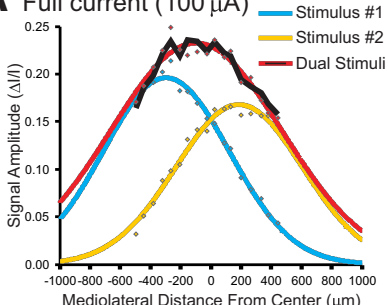

B Half current $(50 \mu \mathrm{A})$

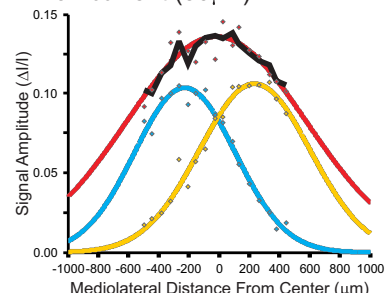

Mediolateral Distance From Center ( $\mu \mathrm{m})$

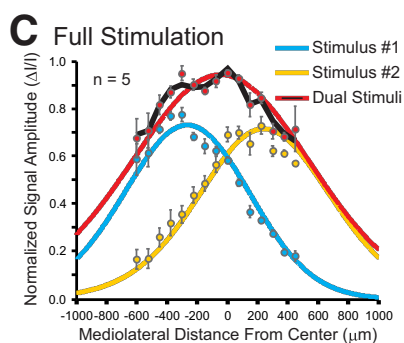

$E$

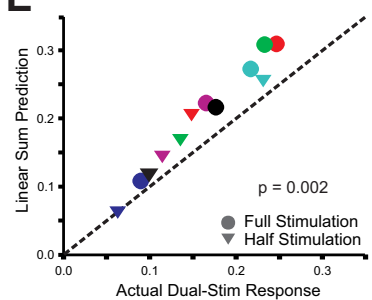

Figure 5. Dual-site stimulation responses show sublinear summation and response normalization. Signal amplitude $(\Delta / / /)$ measured in the SGS from one slice following dual-site stimulation is plotted along the mediolateral extent of the SC. A, Symmetrical full current $(100 \mu \mathrm{A})$ and $(\boldsymbol{B})$ Symmetrical half current (50 $\mu \mathrm{A}$ ) for single-site (blue and yellow) and dual-site (red) stimulation. Gaussians are fitted to the single- and dual-site data. The black lines are the normalization model fits to the dual stimulation data. $C$, Mediolateral distribution of signal amplitude $(\Delta I / /)$ throughout the SGS following full current stimulation (single, blue and yellow; dual-site, red) for five slices with similar interstimulus distances (mean interstimulus distance $\pm S D=607 \pm 67 \mu \mathrm{m}$ ). Colored lines show the Gaussian fits to the data. Black lines show normalization model fits to the dual-site data. $\boldsymbol{D}$, Same as in $($ for the half current stimulation. $\boldsymbol{E}$, Comparison of the Gaussian amplitude parameter (a1) following dual-site stimulation (abscissa) to the Gaussian amplitude parameter of the linear summation of responses to stimulation of site 1 and site 2 (ordinate). Colors indicate data pairs; filled circles, full stimulation; filled triangles, half stimulation. Dashed line is unity. Points falling below the line indicate that the actual, measured response amplitude was reduced compared with that predicted by a linear sum model.

tent with a process of response normalization. Figure 4 illustrates the differences in the fits generated by the linear sum model (green line), the weighted linear sum model (dashed black line), and the divisive normalization model (solid black line) when applied to the population of data $(n=7)$ from Figure $3 B$. The linear sum model does not capture the dual stimulation results, whereas the weighted sum and divisive normalization models do (Fig. 4B,C). Therefore, divisive normalization was used for data fits when applicable.

To rule out response saturation as an explanation for the scaling of the responses, we tested responses to current intensity reduced by half. Figure $5 \mathrm{~A}$ shows the plots of signals resulting from single (blue and yellow) and dual-site (red) stimulation with $100 \mu \mathrm{A}$, and Figure $5 B$ shows the corresponding signals resulting from $50 \mu \mathrm{A}$. With $100 \mu \mathrm{A}$ (full) stimulation at both sites in the SGI (SGI interstimulus distance $=523 \mu \mathrm{m}$ ), the signal in the SGS appeared as a single peak with maximal activity located between the two sites (Fig. 5A, $-96 \mu \mathrm{m}$, red). This location was
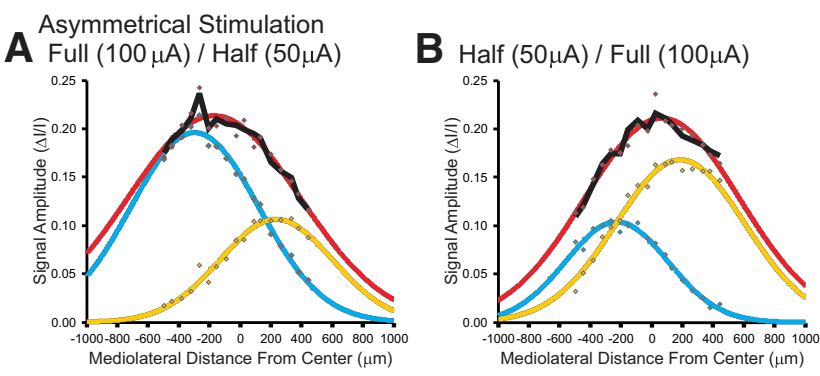

Figure 6. Response normalization predicts the population response to asymmetrical stimulation. $\boldsymbol{A}, \boldsymbol{B}$, Same as in Figure 5, $A$ and $B$, for asymmetrical stimulation at two sites in the SC.

comparable to the mean location of the two individual stimulation sites $(-54 \mu \mathrm{m})$. Similarly, when the current was halved, the location of the peak response appeared between the two singlesite response peaks (Fig. $5 B,-17 \mu \mathrm{m}$, red). This location was again comparable to the mean of the two individual sites $(5 \mu \mathrm{m})$. The dual stimulation data for both full and half current delivery were well fit with both the linear weighed sum model and the normalization model (normalization model fits shown with black lines; Fig. $\left.5 A, R^{2}=0.91 ; B, R^{2}=0.70\right)$. At full stimulation strength, the mean weight ( $w_{1}$ and $w_{2}$ pooled) of the fits to the responses in the SGS using the linear weighted sum model was 0.61 and at half stimulation strength, the mean weight of the fits was 0.49 . Figure $5, C$ and $D$, shows that the SGS responses to full and half current delivery were comparable throughout a population of slices with similar interstimulus distances (mean interstimulus distance $\pm \mathrm{SD}=607 \pm 67 \mu \mathrm{m}, n=5$ ). Since the patterns of activity were largely unchanged when the applied current was halved, it is unlikely that saturation was the cause of the scaling observed in dual stimulation data. The population mean weight ( $w_{1}$ and $w_{2}$ pooled) obtained using the linear weighted sum model was $0.63 \pm 0.07$ following full stimulation and $0.66 \pm$ 0.13 following half stimulation $(n=10)$. Thus, current strength did not alter the mean weight of the weighted linear sum model (Wilcoxon rank sum, $p=0.69$ ). We found very similar results when we fitted the responses using the normalization model. The population mean weights were $0.71 \pm 0.12$ following full stimulation and $0.71 \pm 0.15$ following half stimulation $(n=10)$. Figure $5 E$ shows that SGS responses to dual stimulation were smaller than that predicted by a linear sum model independent of the stimulation strength applied, indicating that the response scaling we observed with dual-site stimulation was not a result of saturation and, therefore, likely reflects an intrinsic normalization mechanism. The differences between the predicted and the actual values across the sample were statistically significant (signed rank, $p=0.002$ ).

In addition to full and half current delivered symmetrically to each stimulation site, we also assessed evoked responses when unequal stimulation intensities were delivered to the two sites. We hypothesized that the peak location of the evoked responses would be biased toward the site with the higher current intensity. Figure 6, $A$ and $B$, shows the responses for asymmetrical stimulation conditions. When the higher current appeared at the site indicated by the blue curve, the peak of the dual response (red curve) was shifted toward the blue peak (Fig. 6A). The center of the Gaussian fit to the site indicated in blue was $-295 \mu \mathrm{m}$ and the site indicated in yellow was $236 \mu \mathrm{m}$. If the two stimuli contributed equally to the dual response, we would expect the peak to occur around the center at $-29 \mu \mathrm{m}$ (the mean of the two locations). However, the Gaussian fit to the dual stimulation response 
was centered at $-169 \mu \mathrm{m}$ (red curve) indicating that the peak of the response was shifted toward the location of stronger stimulation. Similarly, higher current appearing at the site indicated by the yellow curve in Figure $6 B$ shifted the peak of the dual-site response toward the yellow peak. The center for the site indicated in yellow was $187 \mu \mathrm{m}$ and the center for site indicated in blue was $-227 \mu \mathrm{m}$. The dual-site stimulation response (red) was centered at $68 \mu \mathrm{m}$, to the right of the predicted center of $-20 \mu \mathrm{m}$. Finally, both the weighted linear summation model and the normalization model fit the dual-site stimulation responses well and the two models gave rise to the same goodness-of-fit (Fig. $6 A, B$; normalization model shown with black lines; $R^{2}$ values of 0.96 and 0.94 ). The weight for the response evoked by the stronger stimulation was greater $(0.81$ and 0.82 in Fig. $6 A$ and $B$, respectively) than the weight for the response evoked by the weaker stimulation (0.61 and 0.49 in Fig. $6 A$ and $B$, respectively). Based on these results, we conclude that the responses observed in the superficial layers of the SC in response to stimulation of two sites simultaneously in the intermediate layers of the SC do not result from a saturation of responses (Fig. 4). Rather, sublinear summation and response normalization appear to be the rules followed by SC circuits.

The pattern of response integration in vitro resembles that proposed to underlie a behavioral phenomenon called the global effect or saccade averaging (Findlay, 1982; Ottes et al., 1984; van Opstal and van Gisbergen, 1990; Van Opstal et al., 1990; Glimcher and Sparks, 1993; Edelman and Keller, 1998). Simultaneous presentation of two targets to humans or nonhuman primates generates two classes of eye movements. With small angular separation between the targets, an averaged saccade arrives at a location between the two visual stimuli. Alternatively, with a large angular separation, saccades arrive at one target location or the other. How neuronal circuits produce these different behaviors remains unknown. To assess our in vitro results critically in the context of saccade averaging we designed psychophysical experiments in humans that mirror our in vitro experiments and compared human saccadic choice with varying angular separations to in vitro SC population responses to dual-site stimulation with varying distances of separation. These experiments were performed to determine whether there was a correlation between results obtained in slices and those obtained with human behavior.

Human eye movements were recorded from five subjects (three experienced and two naive) following single or dual target presentation with angular separations between targets ranging from 30 to $80^{\circ}$ (Fig. 7). Subjects were instructed to make a saccade as quickly and accurately as possible following target presentation. The saccades made in the dual target condition were divided into three categories based on their endpoints: centrally located (ranging $0 \pm 7.5^{\circ}$; Fig. $7 C$, green), adjacent (between targets, not
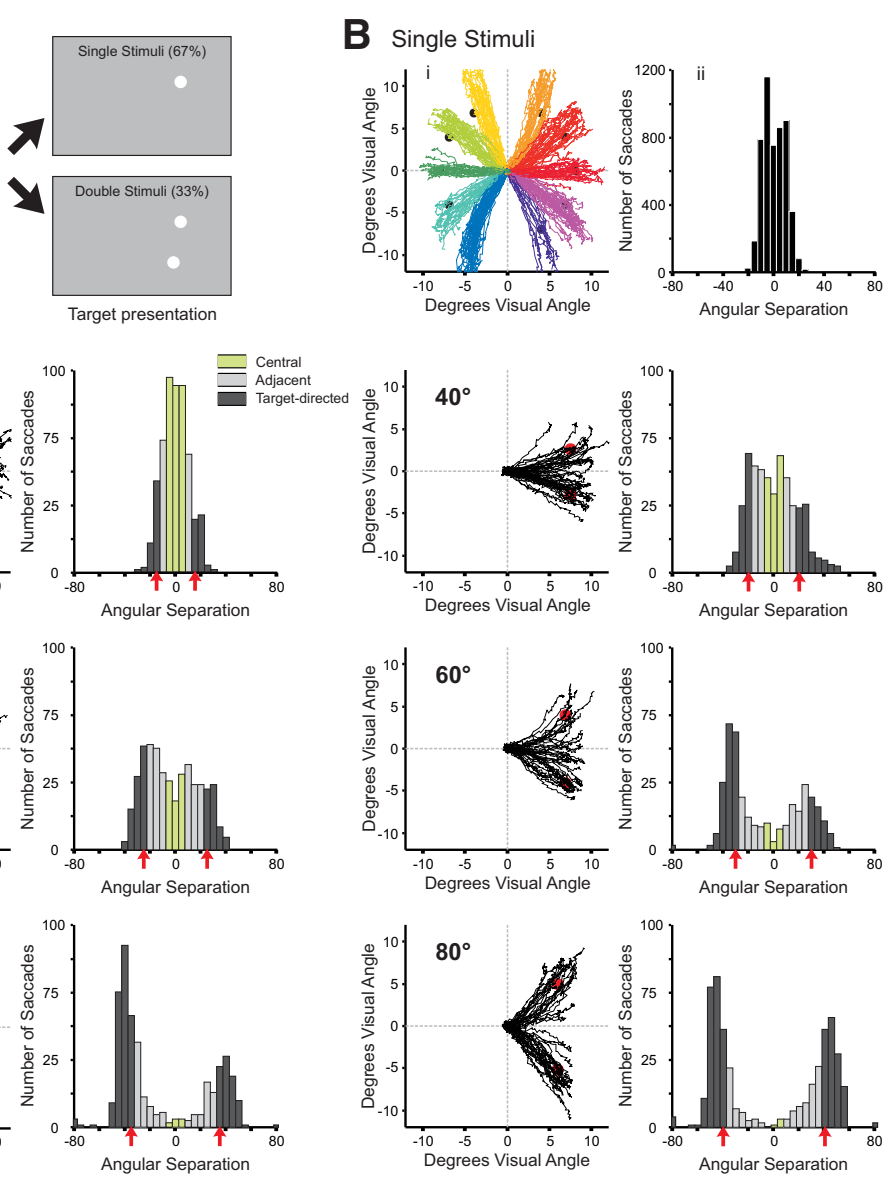

Figure 7. The transition between winner-takes-all and averaging is gradual. $A$, Schematic of the task performed by five human subjects in response to $(\boldsymbol{B})$ single- or $(\boldsymbol{C})$ dual-target presentation. The single-target trials appeared $67 \%$ of the time, whereas the categories: centrally located (green), adjacent (light gray), and target directed (dark gray). Red dots and arrows show the location of target stimuli $\left(30^{\circ}, n=523 ; 40^{\circ}, n=529 ; 50^{\circ}, n=531 ; 60^{\circ}, n=412 ; 70^{\circ}, n=479 ; 80^{\circ}, n=516\right)$.

including centrally located; Fig. $7 C$, light gray), and target directed (on target and beyond; Fig. $7 C$, dark gray). At the smallest angular separation (Fig. $7 C ; 30^{\circ}$ ), 53.5\% of saccadic endpoints fell within the central range, indicating that the eye movements ended at the averaged location of the two stimuli more often than at the adjacent $(23.5 \%)$ or target-directed $(22.9 \%)$ locations. In fact, the distribution of averaged saccadic endpoints closely resembled the distribution of saccadic endpoints following the single target presentation at $0^{\circ}$ (Fig. $7 B$ ). As angular separation increased (Fig. $7 C ; 40,50,60,70$, and $80^{\circ}$ ), the distribution of endpoints widened and the percentage of centrally directed saccades decreased $(27.2,17.9,6.6,2.1$, and $1.0 \%$, respectively), demonstrating a reduced probability of centrally directed saccades. Furthermore, because averaging saccades can fall outside of the central range, central and adjacent (all nontarget-directed) endpoints when combined, showed a similar trend: as target separation increased, the percentage of nontarget-directed saccades decreased $\left(30,40,50,60,70\right.$, and $80^{\circ} ; 77.0,62.0,64.2,43.0,30.1$, and $27.9 \%$, respectively), and the percentage of target-directed saccadic endpoints increased $\left(30,40,50,60,70\right.$, and $80^{\circ} ; 22.9$, $38.0,35.8,57.0,69.9$, and 72.1\%, respectively). Target-directed saccades outpaced averaging saccades (central and adjacent) by $60^{\circ}$ (Fig. 7C). At large angular separations, distributions of sac- 


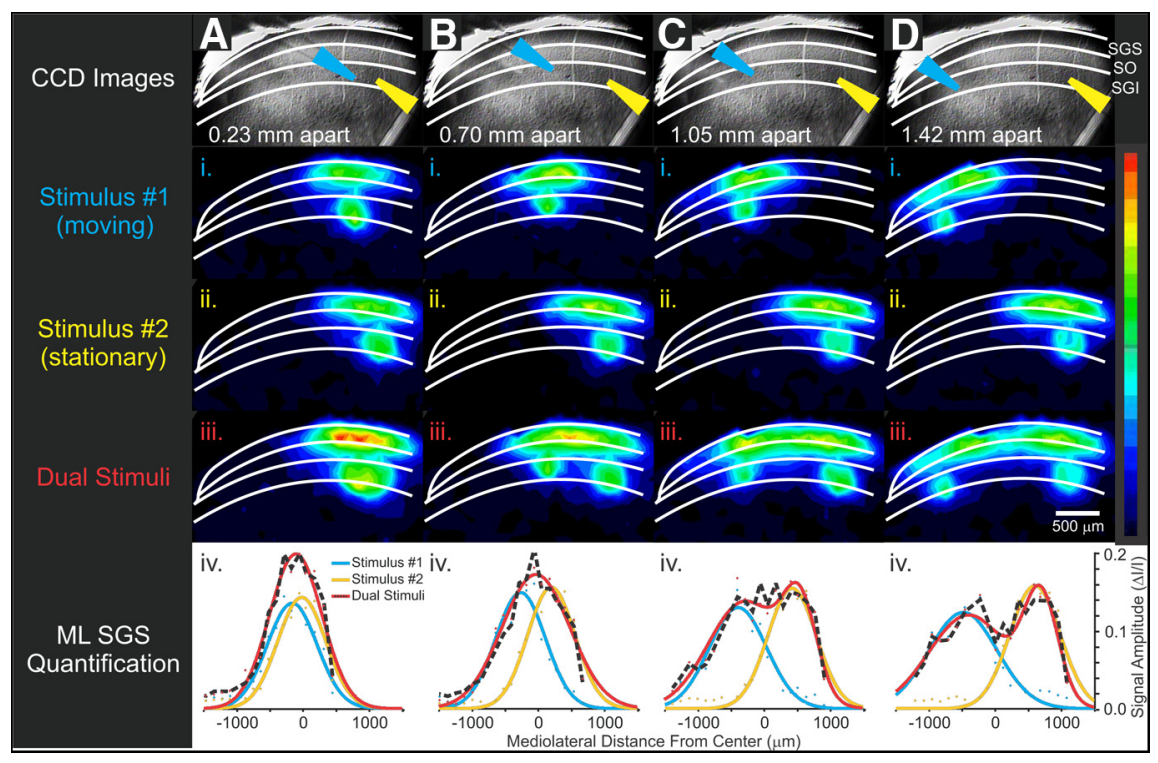

Figure 8. Distance-dependent integration. CCD images and spatial response maps with signal amplitude $(\Delta / / I)$ encoded as color as in Figure 1 following dual-site electrical stimulation at $(\boldsymbol{A}) 0.23 \mathrm{~mm}$ separation, $(\boldsymbol{B}) 0.70 \mathrm{~mm}$ separation, $(\boldsymbol{C}) 1.05 \mathrm{~mm}$ separation, and (D) $1.42 \mathrm{~mm}$ separation. Scale bar, $500 \mu \mathrm{m}$. Arrowheads show the locations of stimulus site 1 (blue) and stimulus site 2 (yellow). Ai-Di, Show color maps following stimulation at site 1. Aii-Dii, Show color maps following stimulation at site 2. Aiii-Diii, Show color maps following dual-site stimulation. Aiv-Div, Show signal amplitude ( $\Delta / / I)$ throughout the SGS following single-site (blue and yellow) and dual-site (red) electrical stimulation. Gaussian (colored lines) and linear weighted sum models (black dashed lines) were fit to the data. The correlation coefficients and the weights for the fits shown in $A v-D v$ are as follows: $R^{2}$ $=0.99, w_{1}=0.81, w_{2}=0.57 ; R^{2}=0.96, w_{1}=0.66, w_{2}=0.71 ; R^{2}=0.94, w_{1}=0.84, w_{2}=0.82 ; R^{2}=0.94, w_{1}=1.0 \mathrm{~m}$ $w_{2}=0.89$.

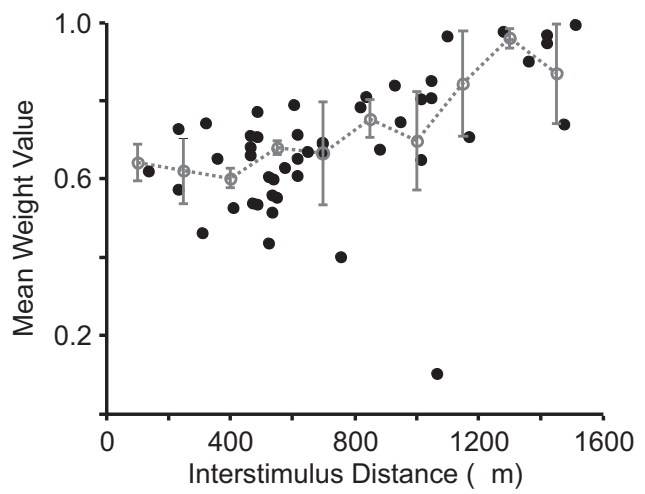

Figure 9. Mean weights increase with interstimulus distance. Mean weight values ( $w_{1}$ and $w_{2}$ pooled) from the weighted linear sum model (Eq. 3) (filled black circles) are shown over a range of interstimulus distances $(n=50)$. Population data were pooled, binned, and plotted with SEM (dotted gray lines and circles).

cadic endpoints resembled two single-target distributions, centered at each target location with tails skewed toward $0^{\circ}$. These data reveal a progression from averaging saccades (central and adjacent) to nonaveraging (target-directed) saccades as the distance between visual targets increased. This observation is important because it indicates that the transition from an averaging read-out to a winner-takes-all read-out is not abrupt but is gradual (Ferrera and Lisberger, 1995; Groh et al., 1997; Recanzone and Wurtz, 1999; Li and Basso, 2005).

We next compared the angular dependence of saccadic choices with the distance dependence of dual-site stimulation responses in the SC to test whether the changes in SC activity could explain the changes in the saccade choices measured in humans. Figure 8 shows an SC slice in which four interstimulus distances were tested. At the smallest interstimulus distance (Fig. $8 A, 0.23 \mathrm{~mm}$ ), Gaussian curves fit to single-site stimulation data are almost overlapping (blue and yellow curves, centered at -158 and $-13 \mu \mathrm{m}$, respectively) and the responses to dual-site stimulation increased at an intermediate location (Fig. 8Aiv; red curve centered at $\left.-105 \mu \mathrm{m}, R^{2}=0.94\right)$. The center of the Gaussian fit to the dual-site response data was comparable to the mean of the two individual stimulation sites $(-85 \mu \mathrm{m})$. As the interstimulus distance increased to $0.70 \mathrm{~mm}$ (Fig. $8 B$ ), dual-site stimulation evoked a signal in the SGS centered at an intermediate location for which a single Gaussian fit the data well (blue and yellow curves centered at -263 and $201 \mu \mathrm{m}$, respectively; red curve centered at $\left.-31 \mu \mathrm{m}, R^{2}=0.96\right)$. At an even greater interstimulus distance, $1.05 \mathrm{~mm}$, single-site stimulation curves peaked at -393 and $425 \mu \mathrm{m}$ (Fig. $8 C$; blue and yellow curves, respectively). Dual stimulation responses at this interstimulus distance, however, were not associated with an increase at the intermediate location $(16 \mu \mathrm{m})$. A double Gaussian fit the data better than a single Gaussian, indicating that at this distance the activity does not merge (Fig. $8 C$, single $R^{2}=0.76$; double $R^{2}=0.90$ ). Figure $8 D$ (1.42 $\mathrm{mm}$ interstimulus distance) shows an even more exaggerated example of the effect of interstimulus distance. Single-site stimulation curves peaked at -479 and $607 \mu \mathrm{m}$ (blue and yellow curves, respectively), and almost no signal was observed at the intermediate location $(64 \mu \mathrm{m})$. Again, a double Gaussian fit the dual stimulation data much better than a single Gaussian (Fig. $8 D$; single $R^{2}=-0.19$, double $R^{2}=0.84$ ). These results show that as the interstimulus distance increases, dual-site stimulation in the SGI is less likely to show merged population responses centered at a location intermediate to the locations of the single stimulation sites. Figure 10 quantifies this finding across the population of SC slices tested (discussed below).

We next assessed the manner in which the activity merged by fitting these data with the linear weighted summation model. The dashed black lines in Figure 8Aiv-Div represents the fits of this model to the dual-site stimulation data; the weighted linear summation model fit the data well $\left(R^{2}\right.$ values ranging from 0.94 to 0.99 ). Stronger response normalization (indicated by smaller weights) occurred when the distance between the two stimulation sites was smaller. At the four separations from the smallest to the largest (Fig. 7Aiv-Div), the averaged weights of $w 1$ and $w 2$ were $0.6,0.6,0.83$, and 0.95 respectively. To ensure that this finding was not unique to this sample slice, mean weights were compared for a subset of slices in which both small and large interstimulus distances were tested in the same slice $(n=7)$. The mean weight of the small interstimulus group (mean interstimulus distance \pm $\mathrm{SD}=601 \pm 100 \mu \mathrm{m})$ was $0.69 \pm 0.05$, whereas the mean weight of the large interstimulus group (mean interstimulus distance \pm $\mathrm{SD}=1387 \pm 111 \mu \mathrm{m}$ ) was $0.90 \pm 0.12$. The difference between these values was statistically significant (Wilcoxon rank sum, $p=$ 0.007 ), indicating that the mean weight depends on interstimulus distance. Figure 9 quantifies this finding for the weights across the 


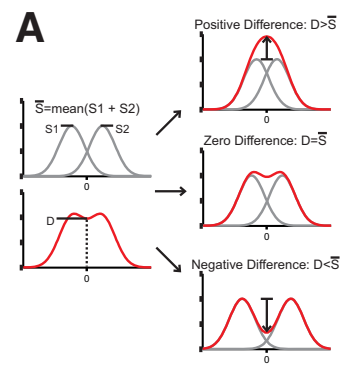

B In Vitro Response



Angular Separation of Targets $\left({ }^{\circ}\right)$

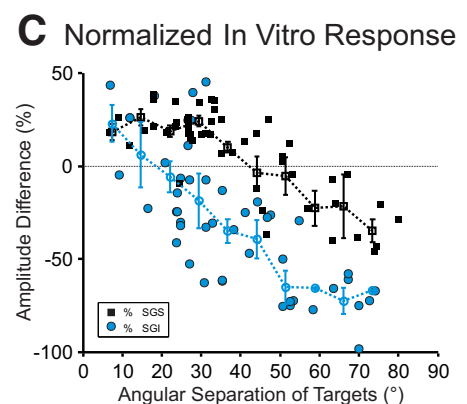

D Human Saccade Endpoints

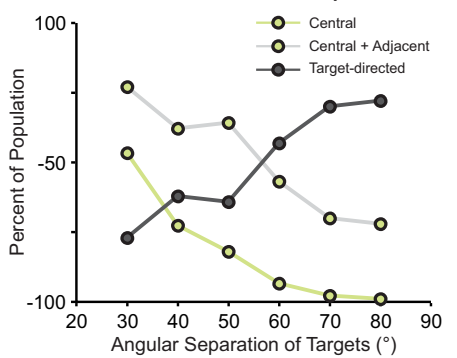

Figure 10. Population integration and saccade averaging are determined by distance and angular separation. $\boldsymbol{A}$, , Changes in signal amplitude $(\Delta / /)$ are expressed as the difference between mean peak amplitude (mean S) of single-site stimulus distributions (S1 and S2, gray) and the amplitude of dual-site stimulus distributions (D, red) at zero interstimulus distance. $\boldsymbol{B}$, Actual and ( $\boldsymbol{C}$ ) percentage differences for voltage signals within the SGS (black symbols) and SGI (blue symbols) are shown over a range of projected angular separations of targets, as calculated from equations modified from 0ttes et al. 1986) (Eqs. 7 and 8; see Materials and Methods; $n=51$ ). Population data were pooled, binned, and plotted with SEMs (dotted lines). $\boldsymbol{D}$, Percentages of central (light green), central + adjacent (light gray), and target-directed (dark gray) saccadic endpoints are plotted across the range of tested target separations.

population of SC slices tested, demonstrating a gradual increase in mean weight as interstimulus distance increases.

To compare the results from rat SC slices directly with the results we obtained in humans making eye movements, we applied the efferent mapping system adapted by Ottes et al. (1996) from the original work in primary visual cortex (V1; Schwartz, 1980), with the equations modified to approximate the dimensions of the rodent SC (Siminoff et al., 1966; Eqs. 7 and 8). With these equations, we converted SC space in millimeters to visual space in degrees and therefore conceptualized our in vitro data in terms of visual space. For instance, interstimulus distances $(v)$ of 0.23 and $0.70 \mathrm{~mm}$ (Fig. $8 A, B$ ) correspond to angular separations of 11.8 and $35.4^{\circ}$, respectively. Both fall within the range of saccade averaging observed here (Fig. 7) and previously (Findlay, 1982; Ottes et al., 1984). The most interesting example is the 0.70 $\mathrm{mm}$ (Fig. $8 B, 35.4^{\circ}$ ) condition where the SC exhibited a merged response at an intermediate location within the SGS but not the SGI. At similar target separations $\left(30\right.$ and $40^{\circ}$ ), humans were also likely to show saccade averaging (Fig. $7 C$ ). Figure $8, C$ and $D$, shows stimulation locations corresponding to angular separations of 52.8 and $70.7^{\circ}$, respectively. These angular separations were least likely to evoke averaging saccades in vivo (Fig. 7), and SGS signals correspondingly remained separate in vitro. Thus, the merging of the signals in the SGS in vitro correlates with saccade averaging but the merging in the SGI does not.

Figure 10 quantifies this finding across a wider range of interstimulus distances (stimulus pairs: $n=51$; slices: $N=25$ ). Changes in signal amplitude were calculated by subtracting the mean of the peak amplitude of the single-site stimulation response (mean $\mathrm{S}=(\mathrm{S} 1+\mathrm{S} 2) / 2)$ from the amplitude of dual-site stimulation response at the zero distance (Fig. $10 \mathrm{D}$ ). Positive values indicate the appearance of increased signal at the intermediate location, whereas negative values indicate that the signals remained as two separate populations of activity (Fig. 10A). Overall, dual-site SGI stimulation produced SGS signals with positive values at small angular separations (small interstimulus distances), and negative values at large angular separations (large interstimulus distances). Comparison of data throughout the SGS (black) and SGI (blue) shows a difference in the pattern of activity between the layers. The SGI, where dual-site electrical stimulation was applied, showed almost no appearance of signal at the intermediate location; positive values were only observed at angular separations below $\sim 20^{\circ}(\sim 400 \mu \mathrm{m}$, blue lines). Figure 8Aiii shows an example in which SGI signals appear marginally increased at an intermediate location when the stimulating electrodes were only
$230 \mu \mathrm{m}$ apart. By a distance of $700 \mu \mathrm{m}$, the SGI activity presented as two separate loci, while the SGS signals merged (Fig. 8Biii). In fact, SGS signals showed positive values at angular separations below $\sim 45^{\circ}$ ( $\sim 900 \mu \mathrm{m}$; Fig. $10 B, C$, black lines $)$. The difference between the SGS and SGI is discernible in non-normalized values (Fig. 10B), but is most apparent when the optical signals are normalized to the maximum intensity of the dual stimulation response (Fig. 10C). These results match well with the transition observed in saccadic behavior of humans. For clarity, human central (light green), central + adjacent (light gray), and targetdirected (dark gray) saccadic endpoints are plotted in Figure $10 \mathrm{D}$ over the range of target separations tested $\left(30-80^{\circ}\right)$. The point at which averaging (central + adjacent saccades, light gray line) and target-directed (dark gray line) lines intersect occurred between 50 and $60^{\circ}$ of angular separation. This transition in behavior is analogous to the transition from merging signals to discrete location signals in the SGS we observed with voltage imaging (Fig. $10 B, C$, black). Notably, it is different from the transition point measured in the signals recorded from the SGI (Fig. $10 B, C$, blue). Based on this we conclude that the neuronal population averaging that likely underlies saccadic averaging may occur in the superficial layers of the SC rather than the intermediate layers or downstream as current models suggest.

\section{Discussion}

We used in vitro voltage imaging techniques and human psychophysical techniques to address how two populations of neuronal activation sites within the SC interact and how the integration of activity might give rise to a saccadic eye movement choice. Consistent with other reports, we found that when two stimuli appear in close proximity $\left(<50^{\circ}\right.$ angular separation) and subjects are instructed to make a choice quickly, saccades end at a location in between the locations of the two stimuli. Using rodent brain slices and electrical stimulation, we found that the merging of population activity from two peaks of activity to one occurred when the sites of stimulation were $<900 \mu \mathrm{m}$ apart. This separation corresponds to $\sim 50^{\circ}$ angular separation on the SC map. Thus, the population response to dual-site stimulation of the rodent SC parallels the behavioral response of the human saccadic eye movement system. Despite the differences between the primate and rodent visual systems (Artal et al., 1998; Douglas et al., 2006), this finding is consistent with the evolutionarily conserved nature of the circuits in the SC (Vanegas, 1984; Stein and Meredith, 1993; Wang et al., 2010). Because the voltage imaging experiments were performed in slices, with cortical and other inputs 
removed, these results also indicate that SC circuits alone are capable of integrating signals arising from multiple sites of activation.

Our results also indicate that the computation performed by the SC circuitry is a nonlinear integration, reminiscent of divisive normalization commonly associated with information processing and selective attention in the visual system (Busse et al., 2009; MacEvoy et al., 2009; Reynolds and Heeger, 2009.; Carandini and Heeger, 2011). Unexpectedly, this normalization occurred not in the motor layers of the SC where stimulation was applied and which would presumably generate the saccade in the intact animal, but rather, in the visual sensory layers of the SC. This finding suggests a novel role for the superficial layers in determining saccade choice and possibly underlying the read-out for saccade averaging.

\section{A novel read-out pathway for saccade averaging?}

There are two possible pathways through which the superficial layers might influence the choice of saccade. The first is through the descending pathway from the superficial sensory layers to the intermediate motor layers that is now well documented (Behan and Appell, 1992; Isa et al., 1998; Ozen et al., 2000; Doubell et al., 2003; Saito and Isa, 2005; Vokoun et al., 2010). In this scenario, the integrated signals we observed in the superficial layers should be transmitted back down to the intermediate layers. Looking at time points out to $50 \mathrm{~ms}$ after stimulation in the SGI (recall only a single pulse was presented to each site), we found that signals from the superficial layers propagated ventrally to the motor layers; however, they were not restricted to the center location of the two stimulation sites (data not shown). This observation does not preclude the hypothesis that additional integration occurs further downstream in brainstem structures responsible for saccade generation and not included in our slices (Glimcher and Sparks, 1993; Edelman and Goldberg, 2001). Slice experiments of the brainstem structures will be required to determine this. A second possibility is that the superficial layers of the SC play a role in action selection when faced with options. Indeed, information from the motor layers of the SC encoding the location of the two potential targets could activate a single region within the sensory layers of the SC through a newly identified, ascending excitatory pathway (Ghitani et al., 2012). This activation would result in potentiating the activity of visual pathways through the projections of superficial layer neurons to the lateral geniculate nucleus and the pulvinar (Diamond et al., 1991; Chomsung et al., 2008; Fredes et al., 2012). Activation of these visual pathways might lead to the subject "seeing" a third target which in turn, would lead to the programming of a saccade to the intermediate location. A role for the superficial layers in attentional mechanisms and normalization is consistent with recent work performed in the owl optic tectum, the avian homolog of the mammalian SC (Winkowski and Knudsen, 2008; Mysore et al., 2010). A test of whether the superficial layers are required for saccadic averaging requires a monkey experiment. Dual-site stimulation of the motor layers of the SC could be combined with reversible inactivation of the superficial sensory layers. If the superficial layers of SC are required to produce averaging saccades, this manipulation should alter their occurrence. If regions downstream are responsible, then this manipulation should leave averaging saccades unaltered.

\section{Decoding SC neuronal activity with normalization}

Several models have been proposed to explain the metrics of saccades following visual and electrical stimulation at multiple locations, (Van Gisbergen et al., 1987; Van Opstal and Van Gisbergen, 1989; McIlwain, 1991; Krommenhoek and Wiegerinck, 1998; Findlay and Walker, 1999; Trappenberg et al., 2001; Arai and Keller, 2005; Noto and Gnadt, 2009; Katnani and Gandhi, 2011; van der Willigen et al., 2011). A key feature of each is nonlinearity, usually implemented as a division of the peak activity by the activity of the whole population. But where exactly the nonlinearity is implemented is unknown. Our results provide the first evidence that the circuits within the SC are sufficient to perform such a computation. Additional support for this conclusion can be found in the literature. There are a number of phenomena in the visual system that can be explained by a normalization computation (Carandini and Heeger, 2011) and similar phenomena appear in the SC. For example, neurons in V1 show saturating discharge rates in response to increases in stimulus contrast (Albrecht and Hamilton, 1982). Visually responsive neurons in the SC also show saturating contrast response functions (Li and Basso, 2008). Cross-orientation suppression is when orientation-selective V1 responses are reduced in the presence of a nonpreferred orientation stimulus even though this stimulus is incapable of driving the neuron when presented alone (Carandini et al., 1997). When multiple stimuli appear and one is in the response field of an SC neuron and one is outside of the response field, even in the opposite hemifield, the discharge of SC neurons is reduced compared to when a stimulus is presented in the preferred location alone (Basso and Wurtz, 1997, 1998). Finally, surround suppression is well explained by a normalization model. When a stimulus encroaches on the suppressive surround of a neuron's response field, the discharge of the neuron is reduced (Cavanaugh et al., 2002a, b). SC neurons show similarly suppressed responses with increases in the size of a visual stimulus (Goldberg and Wurtz, 1972). Together the evidence suggests that given multiple stimuli, the signals generated by this sensory input may be integrated within the SC through a process of divisive normalization. Rather than being read out by downstream gaze centers, the result of this computation may prime circuits in the visual system leading to the selection of a single saccade. Future experiments will test behavioral instantiations of the normalization model by measuring saccade averaging in the presence of visual stimuli with varying contrast.

A final conclusion from the work reported here complements a similar conclusion made from our previous work (Vokoun et al., 2010). The circuitry underlying information processing in the superficial layers and the intermediate layers must be different. We report here evidence for stronger response normalization in the SGS compared with the SGI; smaller weights were measured from data fits in the SGS compared with the SGI when the stimulus intensities and distances were similar between the stimulation sites. Assuming normalization in the SC results from activation of GABAergic circuits, this result is consistent with the known higher levels of GABA in the superficial layers compared with the intermediate layers of the SC (Mize 1992). However, since we also found that single pulse stimulation resulted in a larger spread of activation in the SGS than in the SGI, this makes observing response normalization in the SGS more likely. It is unknown what underlying mechanism is responsible for the larger spread in SGS than SGI; it may be that excitatory connections have a longer range in SGS. Future work exploring the circuitry of the neuronal microcircuitry in SC is warranted.

\section{References}

Albrecht DG, Hamilton DB (1982) Striate cortex of monkey and cat: contrast response function. J Neurophysiol 48:217-237. Medline 
Appell PP, Behan M (1990) Sources of subcortical GABAergic projections to the superior colliculus of the cat. J Comp Neurol 302:143-158. CrossRef Medline

Arai K, Keller EL (2005) A model of the saccade-generating system that accounts for trajectory variations produced by competing visual stimuli. Biol Cybern 92:21-37. CrossRef Medline

Artal P, Herreros de Tejada P, Muñoz TedóC, Ntilde O, Green DG (1998) Retinal image quality in the rodent eye. Vis Neurosci 15:597-605. Medline

Basso MA, Wurtz RH (1997) Modulation of neuronal activity by target uncertainty. Nature 389:66-69. CrossRef Medline

Basso MA, Wurtz RH (1998) Modulation of neuronal activity in superior colliculus by changes in target probability. J Neurosci 18:7519-7534. Medline

Becker W, Jürgens R (1979) An analysis of the saccadic system by means of double step stimuli. Vision Res 19:967-983. CrossRef Medline

Behan M, Appell PP (1992) Intrinsic circuitry in the cat superior colliculus: projections from the superficial layers. J Comp Neurol 315:230-243. CrossRef Medline

Behan M, Steinhacker K, Jeffrey-Borger S, Meredith MA (2002) Chemoarchitecture of GABAergic neurons in the ferret superior colliculus. J Comp Neurol 452:334-359. CrossRef Medline

Busse L, Wade AR, Carandini M (2009) Representation of concurrent stimuli by population activity in visual cortex. Neuron 64:931-942. CrossRef Medline

Carandini M, Heeger DJ (2011) Normalization as a canonical neural computation. Nat Rev Neurosci 13:51-62. CrossRef Medline

Carandini M, Heeger DJ, Movshon JA (1997) Linearity and normalization in simple cells of the macaque primary visual cortex. J Neurosci 17:86218644. Medline

Cavanaugh JR, Bair W, Movshon JA (2002a) Nature and interaction of signals from the receptive field center and surround in macaque $\mathrm{V} 1$ neurons. J Neurophysiol 88:2530-2546. CrossRef Medline

Cavanaugh JR, Bair W, Movshon JA (2002b) Selectivity and spatial distribution of signals from the receptive field surround in macaque V1 neurons. J Neurophysiol 88:2547-2556. CrossRef Medline

Chang PY, Jackson MB (2006) Heterogeneous spatial patterns of long-term potentiation in rat hippocampal slices. J Physiol 576:427-443. CrossRef Medline

Chomsung RD, Petry HM, Bickford ME (2008) Ultrastructural examination of diffuse and specific tectopulvinar projections in the tree shrew. J Comp Neurol 510:24-46. CrossRef Medline

Chou IH, Sommer MA, Schiller PH (1999) Express averaging saccades in monkeys. Vision Res 39:4200-4216. CrossRef Medline

Coëffé C, O'Regan JK (1987) Reducing the influence of non-target stimuli on saccade accuracy: predictability and latency effects. Vision Res 27:227240. CrossRef Medline

Coren S, Hoenig P (1972) Effect of non-target stimuli upon length of voluntary saccades. Percept Motor Skills 34:499-508. CrossRef Medline

Diamond IT, Conley M, Fitzpatrick D, Raczkowski D (1991) Evidence for separate pathways within the tecto-geniculate projection in the treeshrew. Proc Natl Acad Sci U S A 88:1315-1319. CrossRef Medline

Doubell TP, Skaliora I, Baron J, King AJ (2003) Functional connectivity between the superficial and deeper layers of the superior colliculus: an anatomical substrate for sensorimotor integration. J Neurosci 23:65966607. Medline

Douglas RM, Neve A, Quittenbaum JP, Alam NM, Prusky GT (2006) Perception of visual motion coherence by rats and mice. Vision Res 46:28422847. CrossRef Medline

Edelman JA, Goldberg ME (2001) Dependence of saccade-related activity in the primate superior colliculus on visual target presence. J Neurophysiol 86:676-691. Medline

Edelman JA, Keller EL (1998) Dependence on target configuration of express saccade-related activity in the primate superior colliculus. J Neurophysiol 80:1407-1426. Medline

Ferrera VP, Lisberger SG (1995) Attention and target selection for smooth pursuit eye movements. J Neurosci 15:7472-7484. Medline

Findlay JM (1982) Global visual processing for saccadic eye movements. Vision Res 22:1033-1045. CrossRef Medline

Findlay JM, Walker R (1999) A model of saccade generation based on parallel processing and competitive inhibition. Behav Brain Sci 22:661-721. Medline
Fredes F, Vega-Zuniga T, Karten H, Mpodozis J (2012) Bilateral and ipsilateral ascending tectopulvinar pathways in mammals: a study in the squirrel (Spermophilus beecheyi). J Comp Neurol 520:1800-1818. CrossRef Medline

Ghitani N, Vokoun C, Jackson MB, Basso MA (2012) Evidence for an excitatory input from the intermediate to the superficial layers of the rodent superior colliculus. Soc Neurosci Abstr 38:373.07.

Glimcher PW, Sparks DL (1993) Representation of averaging saccades in the superior colliculus of the monkey. Exp Brain Res 95:429-435. Medline

Goldberg ME, Wurtz RH (1972) Activity of superior colliculus in behaving monkey: I. Visual receptive fields of single neurons. J Neurophysiol 35: 542-559. Medline

Groh JM, Born RT, Newsome WT (1997) How is a sensory map read Out? Effects of microstimulation in visual area MT on saccades and smooth pursuit eye movements. J Neurosci 17:4312-4330. Medline

Hays AV, Richmond BJ, Optican LM (1982) A UNIX-based multiple process system for real-time data acquisition and control. WESCON Conf Proc 2:1-10.

Heuer HW, Britten KH (2002) Contrast dependence of response normalization in area MT of the rhesus macaque. J Neurophysiol 88:3398-3408. CrossRef Medline

Isa T, Endo T, Saito Y (1998) The visuo-motor pathway in the local circuit of the rat superior colliculus. J Neurosci 18:8496-8504. Medline

Katnani HA, Gandhi NJ (2011) Order of operations for decoding superior colliculus activity for saccade generation. J Neurophysiol 106:1250-1259. CrossRef Medline

Krommenhoek KP, Wiegerinck WA (1998) A neural network study of precollicular saccadic averaging. Biol Cybern 78:465-477. CrossRef Medline

Li X, Basso MA (2005) Competitive stimulus interactions within single response fields of superior colliculus neurons. J Neurosci 25:11357-11373. CrossRef Medline

Li X, Basso MA (2008) Preparing to move increases the sensitivity of superior colliculus neurons. J Neurosci 28:4561-4577. CrossRef Medline

MacEvoy SP, Tucker TR, Fitzpatrick D (2009) A precise form of divisive suppression supports population coding in the primary visual cortex. Nat Neurosci 12:637-645. CrossRef Medline

Marín G, Mpodozis J, Sentis E, Ossandón T, Letelier JC (2005) Oscillatory bursts in the optic tectum of birds represent re-entrant signals from the nucleus isthmi pars parvocellularis. J Neurosci 25:7081-7089. CrossRef Medline

Marín G, Salas C, Sentis E, Rojas X, Letelier JC, Mpodozis J (2007) A cholinergic gating mechanism controlled by competitive interactions in the optic tectum of the pigeon. J Neurosci 27:8112-8121. CrossRef Medline

McIlwain JT (1991) Distributed spatial coding in the superior colliculus: a review. Vis Neurosci 6:3-13. CrossRef Medline

Mize RR (1992) The organization of GABAergic neurons in the mammalian superior colliculus. Prog Brain Res 90:219-248. CrossRef Medline

Mysore SP, Asadollahi A, Knudsen EI (2010) Global inhibition and stimulus competition in the owl optic tectum. J Neurosci 30:1727-1738. CrossRef Medline

Noto CT, Gnadt JW (2009) Saccade trajectories evoked by sequential and colliding stimulation of the monkey superior colliculus. Brain Res 1295: 99-118. CrossRef Medline

Ottes FP, Van Gisbergen JA, Eggermont JJ (1984) Metrics of saccade responses to visual double stimuli: two different modes. Vision Res 24: 1169-1179. CrossRef Medline

Ottes FP, Van Gisbergen JA, Eggermont JJ (1986) Visuomotor fields of the superior colliculus: a quantitative model. Vision Res 26:857-873. CrossRef Medline

Ozen G, Augustine GJ, Hall WC (2000) Contribution of the superficial layer neurons to premotor bursts in the superior colliculus. J Neurophysiol $84: 460-471$. Medline

Port NL, Wurtz RH (2003) Sequential activity of simultaneously recorded neurons in the superior colliculus during curved saccades. J Neurophysiol 90:1887-1903. CrossRef Medline

Recanzone GH, Wurtz RH (1999) Shift in smooth pursuit initiation in MT and MST neuronal activity under different stimulus conditions. J Neurophysiol 82:1710-1727. Medline

Reynolds JH, Heeger DJ (2009) The normalization model of attention. Neuron 61:168-185. CrossRef Medline

Robinson DA (1972) Eye movements evoked by collicular stimulation in the alert monkey. Vis Res 12:1795-1808. CrossRef Medline 
Saito Y, Isa T (2005) Organization of interlaminar interactions in the rat superior colliculus. J Neurophysiol 93:2898-2907. CrossRef Medline

Sanada TM, Nguyenkim JD, Deangelis GC (2012) Representation of 3-D surface orientation by velocity and disparity gradient cues in area MT. J Neurophysiol 107:2109-2122. CrossRef Medline

Schwartz EL (1980) Computational anatomy and functional architecture of striate cortex: a spatial mapping approach to perceptual coding. Vision Res 20:645-669. CrossRef Medline

Siminoff R, Schwassmann HO, Kruger L (1966) An electrophysiological study of the visual projection to the superior colliculus of the rat. J Comp Neurol 127:435-444. Medline

Stein BE, Meredith MA (1993) The merging of the senses. Cambridge, MA: MIT.

Trappenberg TP, Dorris MC, Munoz DP, Klein RM (2001) A model of saccade initiation based on the competitive integration of exogenous and endogenous signals in the superior colliculus. J Cogn Neurosci 13:256271. CrossRef Medline

van der Willigen, RF Goossens HH, van Opstal AJ (2011) Linear visuomotor transformations in midbrain superior colliculus control saccadic eye movements. J Integr Neurosci 10:277-301. CrossRef Medline

Van Gisbergen JAM, Van Opstal AJ, Tax AAM (1987) Collicular ensemble coding of saccades based on vector summation. Neuroscience 21:541555. CrossRef Medline
Van Opstal AJ, Van Gisbergen JA (1989) A nonlinear model for collicular spatial interactions underlying the metrical properties of electrically elicited saccades. Biol Cybern 60:171-183. Medline

van Opstal AJ, van Gisbergen JA (1990) Role of monkey superior colliculus in saccade averaging. Exp Brain Res 79:143-149. Medline

Van Opstal AJ, Van Gisbergen JA, Smit AC (1990) Comparison of saccades evoked by visual stimulation and collicular electrical stimulation in the alert monkey. Exp Brain Res 79:299-312. CrossRef Medline

Vanegas H, ed (1984) Comparative neurology of the optic tectum. New York: Plenum.

Vokoun CR, Jackson MB, Basso MA (2010) Intralaminar and interlaminar activity within the rodent superior colliculus visualized with voltage imaging. J Neurosci 30:10667-10682. CrossRef Medline

Wang L, Sarnaik R, Rangarajan K, Liu X, Cang J (2010) Visual receptive field properties of neurons in the superficial superior colliculus of the mouse. J Neurosci 30:16573-16584. CrossRef Medline

Winkowski DE, Knudsen EI (2007) Top-down control of multimodal sensitivity in the barn owl optic tectum. J Neurosci 27:13279-13291. CrossRef Medline

Winkowski DE, Knudsen EI (2008) Distinct mechanisms for top-down control of neural gain and sensitivity in the owl optic tectum. Neuron 60:698-708. CrossRef Medline 